J Am Chem Soc. 2016 June 29; 138(25): 7824-7827. doi:10.1021/jacs.6b03384.

\title{
Nickel-Catalyzed Asymmetric Kumada Cross-Coupling of Symmetric Cyclic Sulfates
}

\author{
Meredith S. Eno, Alexander Lu, and James P. Morken ${ }^{*}$ \\ Department of Chemistry, Merkert Chemistry Center, Boston College, Chestnut Hill, \\ Massachusetts 02467
}

\begin{abstract}
Nickel-catalyzed enantioselective cross- couplings between symmetric cyclic sulfates and aromatic Grignard reagents are described. These reactions are effective with a broad range of substituted cyclic sulfates and deliver products with asymmetric tertiary carbon centers.

Mechanistic experiments point to a stereoinvertive $\mathrm{S}_{\mathrm{N}} 2$-like oxidative addition of a nickel complex to the electrophilic substrate.
\end{abstract}

\section{Graphical Abstract}
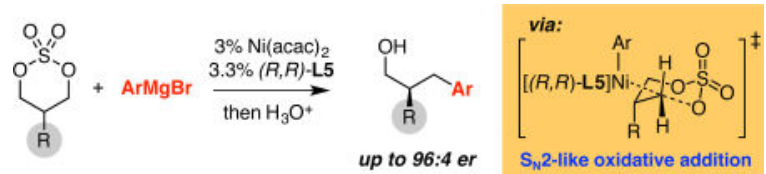

The Kumada coupling ${ }^{1}$ between Grignard reagents and alkyl electrophiles has emerged as an important strategy for the construction of asymmetric carbon centers. ${ }^{2}$ Noteworthy recent advances by $\mathrm{Fu}^{3}$, Zhong and $\mathrm{Bian}^{4}$, and Nakamura ${ }^{5}$ have established enantioconvergent Kumada coupling of secondary alkyl electrophiles ${ }^{6}$ (eq. 1), while Breit ${ }^{7}$, Carretero ${ }^{8}$, and $\mathrm{Jarvo}^{9}$ have demonstrated that, with appropriate catalysts, nonracemic alkyl halides, triflates and ethers may be converted into coupling products enantiospecifically (eq. 2). ${ }^{10} \mathrm{In}$ the prior studies, a general reactivity pattern can be discerned where stereoconvergence occurs with activated racemic secondary alkyl halide electrophiles that engage in single-electron redox reactions with first-row metals: the resulting catalytic cycles operate through prochiral carbon-centered radicals and this feature provides a mechanism for enantioconvergence. In contrast, nonracemic chiral C-O bonded substrates participate in stereo-specific two-electron reactions such that enantiospecific processes result. ${ }^{11}$ While these elegant catalytic coupling methods can address a range of synthesis problems, in order for reactions to occur with useful levels of selectivity and reactivity, substrate designs generally employ activated electrophiles bearing an $\mathrm{sp}^{2}$ hybridized carbon adjacent to the electrophilic center. In this

*morken@bc.edu.

ASSOCIATED CONTENT

Supporting Information. Procedures, characterization and spectral data. This material is available free of charge via the Internet at http://pubs.acs.org.

The authors declare no competing financial interests. 
manuscript we describe a strategy for asymmetric Kumada couplings that involve nonactivated alkyl electrophiles in enantioselective coupling reactions. Because of the nature of the reaction design, this process may be useful for the construction of tertiary, quaternary, and heteroatom substituted stereogenic centers.

Recent studies in our laboratory have engaged prochiral geminal bis(boronates) in enantioselective cross-coupling reactions. ${ }^{12}$ Related to this reaction design, we considered cross-coupling of prochiral bis(electrophiles) as a means to establish chiral motifs from simple readily available starting materials. In this regard, cross-coupling-based enantioselective desymmetrization has been applied in a range of contexts, ${ }^{13}$ including Kumada couplings. ${ }^{14}$ We envisioned that a broadly useful reaction design might arise from the reaction of prochiral cyclic sulfates (eq. 3, Scheme 1). These substrates are readily available from simple 1,3-diols, and they have the following important features: a) with a C$\mathrm{O}$ bonded leaving group, well-defined stereoelectronic effects should steer the trajectory of two-electron inner-sphere redox processes involving metal complexes; b) rupture of the first $\mathrm{C}-\mathrm{O}$ bond in the bis(electrophile) should attenuate the reactivity of the remaining $\mathrm{C}-\mathrm{O}$ bond thereby minimizing competing bis(coupling) reaction; c) the cyclic nature of the electrophile should minimize the number of competing conformational isomers that engage in coupling relative to related acyclic 1,3 bis(electrophiles); d) the nature of the prochiral carbon center is unrelated to the functionality required for the Kumada coupling such that a broad range of substituted stereogenic centers might be established with the same fundamental reaction design.

Cyclic sulfate 1 (Table 1), a compound that is readily prepared on large scale from the solvent 2-methyl-1,3-propandiol ( $\$ 30 /$ liter), was selected as a probe substrate to initiate these studies. While cyclic sulfates are rarely used as electrophiles in catalytic crosscoupling reactions ${ }^{15}$, Kumada, Suzuki, and Negishi couplings of related alkyl sulfonate esters have received attention and serve as instructional models. ${ }^{16}$ Many Kumada couplings involving alkyl sulfonate electrophiles operate with inexpensive readily available nickel catalysts and these were selected for initial study. Preliminary experiments established the following important features: 1) in THF solvent at $0{ }^{\circ} \mathrm{C}$, phenyl magnesium bromide does not undergo uncatalyzed reaction with cyclic sulfate $1 ; 2)$ in the absence of ligand, $\mathrm{Ni}(\operatorname{cod})_{2}$ promotes the coupling of $\mathrm{PhMgBr}$ with $\mathbf{1}$, but in only $20 \%$ conversion after $14 \mathrm{~h}$ at $0{ }^{\circ} \mathrm{C} ; 3$ ) reactions with freshly prepared Grignard reagents give diminished yield and selectivity, thus for effective reaction Grignard reagents were stored for 15 hours at $4{ }^{\circ} \mathrm{C}$ prior to use (we suspect the aging process allows precipitation of $\mathrm{MgBr}_{2} ; \mathrm{MgBr}_{2}$ was found to react directly with cyclic sulfate 1 to furnish a 3-bromopropanol derivative); 4) of a number of phosphorous-based and nitrogen-based ligands, PyBox ligands appeared to be most effective at providing both increased reaction efficiency and selectivity in the Kumada coupling of $\mathbf{1}$ (Table 1). In particular, phenylglycine-derived pybox ligands appeared most effective and a systematic evaluation of substituted versions revealed that ethyl groups at the meta positions (L5) furnished optimal selectivity. While the yields in the initial survey were moderate, further investigation revealed that hydrolysis of the sulfate ester was incomplete (6 hours reaction time) and extending the time for the deprotection step to 24 hours resulted in much higher yields (88\% yield with $\mathbf{L 5}$ ). 
While selectivity in the Kumada coupling of $\mathbf{1}$ with $\mathrm{PhMgBr}$ was very good at $0{ }^{\circ} \mathrm{C}$, it could be improved slightly by conducting the reaction at $-25^{\circ} \mathrm{C}$ and this temperature was selected for analysis of other substrates. As depicted in Table 2, reaction of $\mathbf{1}$ and $\mathrm{PhMgBr}$ furnishes 2 in excellent yield (86\%) and enantioselectivity (96:4 er). Notably, this level of selectivity was maintained with a number of other cyclic sulfate substrates. Thus cyclic sulfates with more hindered ethyl and iso-propyl groups (products 3 and 4) at the prostereogenic carbon were also selectively converted to the derived primary alcohol products in excellent selectivity. In addition to these substrates, phenyl (5), phenethyl (6), and benzyloxymethyl groups (7), were also tolerated as substituents on the electrophile. In addition to phenylmagnesium bromide, other substituted aryl Grignard reagents could participate in the reaction. For example, Grignard reagents bearing meta- and para-alkyl, alkoxy, silyl, fluorine, and chlorine groups (8-16) engaged in the Kumada coupling with 1 in similar high levels of selectivity. Also of note, nitrogen atoms in the form of N-heterocycles did not appear to prohibit the reaction $(\mathbf{1 7}, \mathbf{1 8})$. Lastly, it should be noted that ortho-substituted Grignard reagents, as well as alkyl and alkenyl magnesium halides, reacted with lower yield and gave near-racemic products with the current catalyst system.

With respect to synthesis utility, substituted chromans are core components of a number of biologically-active natural products ${ }^{17}$ and it was considered that some of the products in Table 1 might be suitable precursors for their synthesis. To investigate this feature, primary alcohol 11 was subjected to oxidation with phenyliodine(III) bistrifluoroacetate. ${ }^{18}$ As depicted in Scheme 2 (eq. 4), compound 1 was smoothly converted to chroman 19 in moderate yield and, importantly, with complete preservation of the substrate enantiomeric purity. Also, in connection to synthesis applications, Kumada couplings on larger scale were investigated. As depicted in eq. 5, it was found that the asymmetric coupling conducted on larger scale occurred efficiently and with only a slight diminution in enantiomeric excess. Of note, it was also shown in this experiment that without the acidic deprotection step, the sulfate half-ester $\mathbf{2 0}$ could be isolated and purified by chromatography. Considering the ability of alkyl sulfates to undergo substitution reactions ${ }^{19}$, this should be a useful feature. Lastly, a glycerol derivative was examined in the reaction (eq. 6). While selectivity is diminished in the Kumada coupling of $\mathbf{2 1}$ relative to the hydrocarbon derivatives in Table 2, this example demonstrates that heteroatom functionalized substituted sulfates can also be employed in this class of asymmetric couplings; however, the current catalyst system is ineffective at transforming substrates that would deliver tertiary alcohols derivatives or quaternary centers (inset Scheme 2).

As mentioned in the introduction, cyclic sulfates were selected as substrates for crosscoupling due to the likelihood that they would participate in stereodefined two-electron redox reactions with incoming catalysts. To ascertain whether radical-based processes are indeed avoided under the current reaction conditions, we examined the Kumada coupling of cyclopropyl-containing cyclic sulfate 23 . It was considered that if oxidative addition of a $\mathrm{Ni}$ complex to the $\mathrm{C}-\mathrm{O}$ bond occurs through the intermediacy of a carbon-centered radical, then the cyclopropyl carbinyl radical derived from $\mathbf{2 3}$ would rupture and ultimately deliver $\mathbf{2 5}$ as the reaction product. ${ }^{20}$ However, as depicted in eq. 6 , when subjected to the reaction conditions, only the usual Kumada coupling product $\mathbf{2 4}$ was detected thereby suggesting 
non-radical processes operate. To obtain further insight about the stereochemical aspects of the oxidative addition reaction, isotopically-labeled non-racemic substrate $(4 S, 5 S)-26-d_{1}$ was prepared and subjected to the catalytic reaction in the presence of chiral ligand L5. In comparison to authentic isotopically-labeled compounds, it was determined that reaction of $\mathbf{2 6}$ furnishes stereoisomer $\mathbf{2 7}$ with a high level of stereospecificity (90\%

diastereospecificity). Assuming that a $\mathrm{C}-\mathrm{C}$ bond forming reductive elimination would occur with retention of configuration at carbon, the outcome of the reaction in eq. 7 suggests that oxidative addition occurs with stereoinversion at carbon, presumably by an $\mathrm{S}_{\mathrm{N}} 2$-like reaction path.

In consideration of the above described mechanistic experiments and observations on the substrate scope, we propose the following generalized mechanism for the Ni-catalyzed Kumada coupling of cyclic sulfates. This proposal rests on the assumption that the stereochemistry-determining step of the reaction is ring-opening of the cyclic sulfate by a chiral Ni complex. Because the enantioselectivity in the reaction is impacted by the nature of the Grignard reagent employed in the cross-coupling (compare products 2, 12, and 15), it seems plausible that a pyboxNi(Ar) complex is a reacting species. While the low energy conformation of the cyclic sulfate substrate is likely one with an equatorially-disposed C5 substituent ${ }^{21}(\mathbf{B})$, considering the similar levels of selectivity and efficiency observed in formation of products $\mathbf{2 , 3}$ and $\mathbf{4}$ even though the substituent size is very different, suggests that the reactive conformation of the sulfate may be one where the $\mathrm{C} 5$ group is positioned axially (A). By way of backside $\mathrm{S}_{\mathrm{N}}$ 2-like oxidative addition of nickel complex $\mathbf{C}$ to $\mathbf{A}$ ( via TS), a nickel complex akin to $\mathbf{D}$ might be generated. Reductive elimination would furnish a nickel sulfate $\mathbf{E}$ from which $\mathbf{C}$ could be regenerated by reaction with the Grignard reagent.

In conclusion, Ni-catalyzed Kumada coupling of symmetric cyclic sulfates is an effective method for establishing asymmetric carbon centers. With the catalyst system described herein, the reaction occurs with good selectivity for the construction of tertiary hydrocarbon centers. It can be anticipated that further catalyst development will enable reactions that extend to heteroatom-substituted centers and to the construction of all-carbon quaternary centers as well. Studies in this connection are in progress.

\section{Supplementary Material}

Refer to Web version on PubMed Central for supplementary material.

\section{Acknowledgments}

This work was supported by the NIH (GM-64451).

\section{References}

1. Tamao K, Sumitani K, Kumada M. J. Am. Chem. Soc. 1972; 94:4374.(b) Tamao K, Kiso Y, Sumitani K, Kumada M. J. Am. Chem. Soc. 1972; 94:9268.(c) Hayashi T, Tajika M, Tamao K, Kumada M. J. Am. Chem. Soc. 1976; 98:3718.

2. Recent reviews: Frisch AC, Beller M. Angew. Chem. Int. Ed. 2005; 44:674.Glorius F. Angew. Chem. Int. Ed. 2008; 47:8347.Rudolph A, Lautens M. Angew. Chem. Int. Ed. 2009; 48:2656.Tasker SZ, Standley EA, Jamison TF. Nature. 2014; 509:299. [PubMed: 24828188] 
3. Lou S, Fu GC. J. Am. Chem. Soc. 2010; 132:1264. [PubMed: 20050651]

4. (a) Mao J, Liu F, Wang M, Wu L, Zheng B, Liu S, Zhong J, Bian Q, Walsh PJ. J. Am. Chem. Soc. 2014; 136:17662. [PubMed: 25479180] (b) Wu J, Zhong J, Liu S, Liu F, Gao Z, Wang M, Bian Q. Tetrahedron: Asymm. 2016; 27:78.

5. Jin M, Adak L, Nakamura M. J. Am. Chem. Soc. 2015; 137:7128. [PubMed: 25955413]

6. For selected asymmetric coupling of alkyl electrophiles: Negishi couplings: Fischer C, Fu GC. J. Am. Chem. Soc. 2005; 127:4594. [PubMed: 15796523] Arp FO, Fu GC. J. Am. Chem. Soc. 2005; 127:10482. [PubMed: 16045323] Smith SW, Fu GC. J. Am. Chem. Soc. 2008; 130:12645. [PubMed: 18763769] Lundin PM, Esquivias J, Fu GC. Angew. Chem. Int. Ed. 2009; 48:154.Oelke A, Sun J, Fu GC. J. Am. Chem. Soc. 2012; 134:2966. [PubMed: 22296603] Choi J, Fu GC. J. Am. Chem. Soc. 2012; 134:9102. [PubMed: 22612264] Do H-Q, Chandrashekar ER, Fu GC. J. Am. Chem. Soc. 2013; 135:16288. [PubMed: 24164502] Choi J, Martin-Gago P, Fu GC. J. Am. Chem. Soc. 2014; 136:12161. [PubMed: 25127186] Liang Y, Fu GC. J. Am. Chem. Soc. 2015; 137:9523. [PubMed: 26203662] Suzuki couplings: Saito B, Fu GC. J. Am. Chem. Soc. 2008; 130:6694. [PubMed: 18447357] Zultanski SL, Fu GC. J. Am. Chem. Soc. 2011; 133:15362. [PubMed: 21913638] Lundin PM, Fu GC. J. Am. Chem. Soc. 2010; 132:11027. [PubMed: 20698665] Shields JD, Ahneman DT, Graham TJA, Doyle AG. Org. Lett. 2014; 16:142. [PubMed: 24279380] Jiang X, Sakthivel S, Kulbitski K, Nisnevich G, Gandelman M. J. Am. Chem. Soc. 2014; 136:9548. [PubMed: 24958322]

7. Studte C, Breit B. Angew. Chem. Int. Ed. 2008; 47:5451.

8. López-Pérez A, Adrio J, Carretero JC. Org. Lett. 2009; 11:5514. [PubMed: 19943702]

9. (a) Taylor BLH, Swift EC, Waetzig JD, Jarvo ER. J. Am. Chem. Soc. 2011; 133:389. [PubMed: 21155567] (b) Taylor BLH, Harris MR, Jarvo ER. Angew. Chem. Int. Ed. 2012; 51:7790.(c) Greene MA, Yonova IM, Williams FJ, Jarvo ER. Org. Lett. 2012; 14:4293. [PubMed: 22568515] (d) Tollefson EJ, Dawson DD, Osborne CA, Jarvo ER. J. Am. Chem. Soc. 2014; 136:14951. [PubMed: 25308512] (e) Tollefson EJ, Hanna LE, Jarvo ER. Acc. Chem. Res. 2015; 48:2344. [PubMed: 26197033] (f) Dawson DD, Jarvo ER. Org. Proc. Res. Dev. 2015; 19:1356.

10. For a comprehensive review of stereoselective cross-coupling, see: Cherney AH, Kadunce NT, Reisman SE. Chem. Rev. 2015; 115:9587. [PubMed: 26268813]

11. For a mechanistic overview of Ni-catalyzed cross-coupling, see: Hu X. Chem. Sci. 2011; 2:1867. (b) ref $2 \mathrm{~d}$.

12. (a) Sun C, Potter B, Morken JP. J. Am. Chem. Soc. 2014; 136:6534. [PubMed: 24564423] (b) Potter B, Szymaniak AA, Edelstein EK, Morken JP. J. Am. Chem. Soc. 2014; 136:17918. [PubMed: 25482206]

13. Review: Rovis T. New Frontiers in Asymmetric Catalysis. Mikami K, Lautens M. WileyHoboken, NJ2007Selected C-C bond forming examples: Anhydride opening Shintani R, Fu GC. Angew. Chem. Int. Ed. 2002; 41:1057.Bercot EA, Rovis T. J. Am. Chem. Soc. 2004; 126:10248. [PubMed: 15315429] Johnson JB, Bercot EA, Williams CM, Rovis T. Angew. Chem. Int. Ed. 2007; 46:4514.Cook MJ, Rovis T. J. Am. Chem. Soc. 2007; 129:9302. [PubMed: 17622150] Cyclohexadienone additions: Keilitz J, Newman SG, Lautens M. Org. Lett. 2013; 15:1148. [PubMed: 23421491] He Z-T, Tian B, Fukui Y, Tong X, Tian P, Lin G-Q. Angew. Chem. Int. Ed. 2013; 52:5314.Bicycle opening: Lautens M, Fagnou K, Hiebert S. Acc. Chem. Res. 2003; 36:48. [PubMed: 12534304] 2-Ene-1.4-diol substitutions: Trost BM, van Vranken DL. Chem. Rev. 1996; 96:395. [PubMed: 11848758] Epoxide opening: Zhao Y, Weix DJ. J. Am. Chem. Soc. 2015; 137:3237. [PubMed: 25716775] 2- Ene-1,4-dione addition: Aikawa K, Okamoto T, Mikami K. J. Am. Chem. Soc. 2012; 134:10329. [PubMed: 22670680] Oxetane opening: Mizuno M, Kanai M, Iida A, Tomioka K. Tetrahedron: Asymm. 1996; 7:2483.Mizuno M, Kanai M, Iida A, Tomioka K. Tetrahedron. 1997; 53:10699.Suzuki coupling of symmetric ditrifaltes: Willis MC, Powell LHW, Claverie CK, Watson SJ. Angew. Chem., Int. Ed. 2004; 43:1249.C-H activation/coupling: Shi B-F, Maugel N, Zhang Y-H, Yu J-Q. Angew. Chem. Int. Ed. 2008; 47:4882.

14. (a) Hayashi T, Nizuma S, Kamikawa T, Suzuki N, Uozumi Y. J. Am. Chem. Soc. 1995; 117:9101. (b) Kamikawa T, Hayashi T. Tetrahedron. 1999; 55:3455.

15. (a) Tello-Aburto R, Johnson EM, Valdez CK, Maio WA. Org. Lett. 2012; 14:2150. [PubMed: 22475318] (b) Tello-Aburto R, Newar TD, Maio WA. J. Org. Chem. 2012; 77:6271. [PubMed: 22721171] 
16. Catalytic cross-coupling of alkyl sulfonates: see Terao J, Watanabe H, Ikumi A, Kuniyasu H, Kambe N. J. Am. Chem. Soc. 2002; 124:4222. [PubMed: 11960446] Terao J, Naitoh Y, Kuniyasu H, Kambe N. Chem. Lett. 2003; 32:890.Nagano T, Hayashi T. Org. Lett. 2004; 6:1297. [PubMed: 15070321] Terao J, Todo H, Watanabe H, Ikumi A, Kambe N. Angew. Chem. Int. Ed. 2004; 43:6180.Terao J, Naitoh Y, Kuniyasu H, Kambe N. Chem. Commun. 2007:825.Singh SP, Terao J, Kambe N. Tetrahedron Lett. 2009; 50:5644.Ito S, Fujiwara Y, Nakamura E, Nakamura M. Org. Lett. 2009; 11:4306. [PubMed: 19731937] Ren P, Stern L-A, Hu X. Angew. Chem. Int. Ed. 2012; 51:9110. Yang CT, Zhang ZQ, Liang J, Liu JH, Lu XY, Chen HH, Liu L. J. Am. Chem. Soc. 2012; 134:11124. [PubMed: 22734716] Iwasaki T, Imanishi R, Shimizu R, Kuniyasu H, Terao J, Kambe N. J. Org. Chem. 2014; 79:8522. [PubMed: 25010426]

17. Shen HC. Tetrahedron. 2009; 65:3931.

18. Hata K, Hamamoto H, Shiozaki Y, Caemmerer SB, Kita Y. Tetrahedron. 2007; 63:4052.

19. Examples: Itoh S, Hirai T, Totsuka Y, Takagi H, Tashiro Y, Wada K, Wakabayashi K, Shibutani S, Yoshizawa I. Chem. Res. Toxicol. 1998; 11:1312. [PubMed: 9815191] Frazer AS, Kawasaki AM, Jung ME, Manoharan M. Tetrahedron Lett. 2000; 41:1523.Prakash TP, Manoharan M, Fraser AS, Kawasaki AM, Lesnik EA, Owens SR. Tetrahedron Letters. 2000; 41:4855.Fuhrmann H, Grassert I, Holzhüter G, Grüttner C, Oehme G. New. J. Chem. 2002; 26:1675.MacKay JA, Vedejs E. J. Org. Chem. 2006; 71:498. [PubMed: 16408956]

20. For ring-opening in Ni-catalyzed cross-coupling of halomethylcyclopropanes, see: Phapale VB, Buñuel E, García-Iglesias M, Cárdenas DJ. Angew. Chem. Int. Ed. 2007; 46:8790.Vechorkin O, Csok Z, Scopelliti R, Hu X. Chem.-Eur. J. 2009; 15:3889. [PubMed: 19229933]

21. Lowe G, Thatcher GRJ, Turner JCG, Waller A, Watkin DJ. J. Am. Chem. Soc. 1988; 110:8512. 
Previous strategies in asymmetric Kumada Coupling:

Enantioselective Kumada coupling (Fu, Zhong \& Bian, Nakamura):

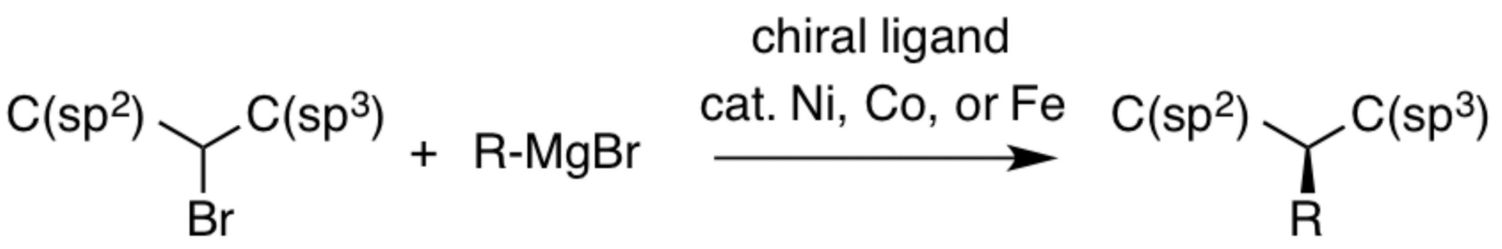

racemic

nonracemic

Enantiospecific Kumada coupling (Breit, Carretero, Jarvo):

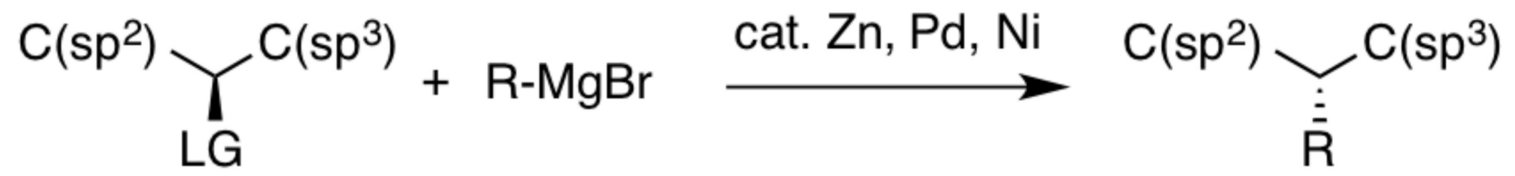

nonracemic

nonracemic

This work: Kumada coupling of prochiral cyclic sulfates:

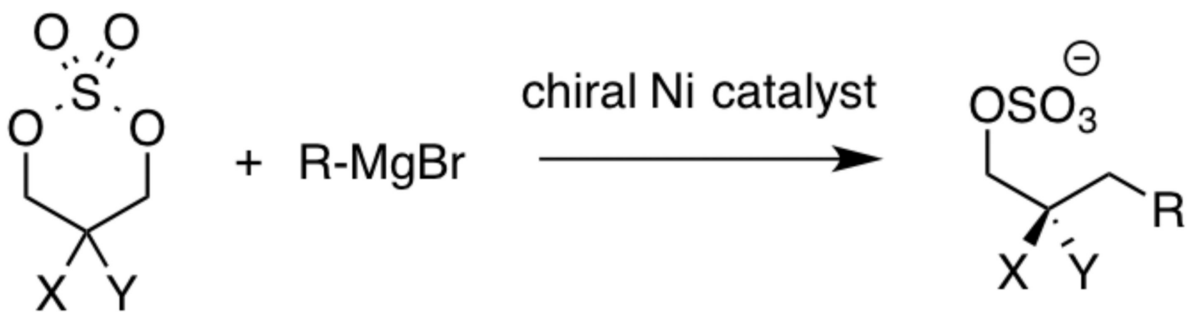

Scheme 1.

Strategies in Stereoselective Kumada Coupling 
<smiles>COc1ccc(C[C@@H](C)CO)cc1</smiles>

11 95:5 er<smiles>CC1COS(=O)(=O)OC1</smiles>

1 (1.0 gram)<smiles>O=S1(=O)OCC(OCc2ccccc2)CO1</smiles>
21

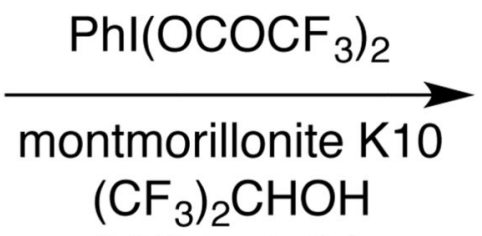

$\mathrm{O}^{\circ} \mathrm{C}$ to rt, $3 \mathrm{~h}$

$\mathrm{Ni}(\mathrm{acac})_{2}(3 \%)$

$(R)$-L5 (3.3\%)

$\mathrm{PhMgBr}$ (1.5 equiv)

THF, $-25^{\circ} \mathrm{C}, 14 \mathrm{~h}$<smiles>COc1ccc2c(c1)C[C@@H](C)CO2</smiles>

$19,53 \%$ y

94:6 er<smiles>C[C@@H](COS(=O)(=O)O)Cc1ccccc1</smiles>

$20,92 \%$ y

92:8 er

1. $\mathrm{Ni}(\mathrm{acac})_{2}(6 \%)$

$(R)-\operatorname{L5}(6.6 \%)$

$\mathrm{PhMgBr}$ (1.5 equiv)

THF, $-25^{\circ} \mathrm{C}, 14 \mathrm{~h}$

2. $\mathrm{H}_{2} \mathrm{SO}_{4}(20 \%, \mathrm{aq})$

rt, $24 \mathrm{~h}$<smiles>OC[C@@H](Br)Cc1ccccc1</smiles>

22, $19 \%$ y

75:25 er

Scheme 2.

Synthesis Utility of Asymmetric Kumada Coupling of Cyclic Sulfates 
<smiles>O=S1(=O)OCC2(CC2)CO1</smiles>

23<smiles>[2H][C@@H]1O[C@H]([CH2])OC[C@H]1[2H]</smiles>

$(4 S, 5 S)-26-d_{1}$

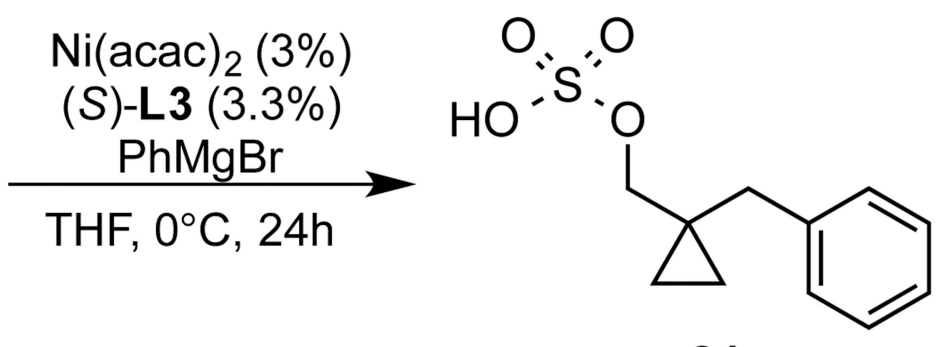

\section{4}

$56 \%$ y

(6)

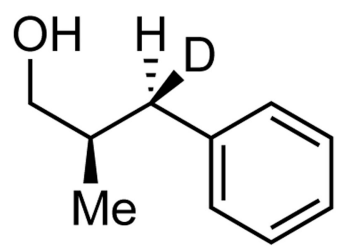

27

Scheme 3.

Mechanistic Experiments on Ni(pybox) Catalyzed Kumada Coupling of Cyclic Sulfates. 


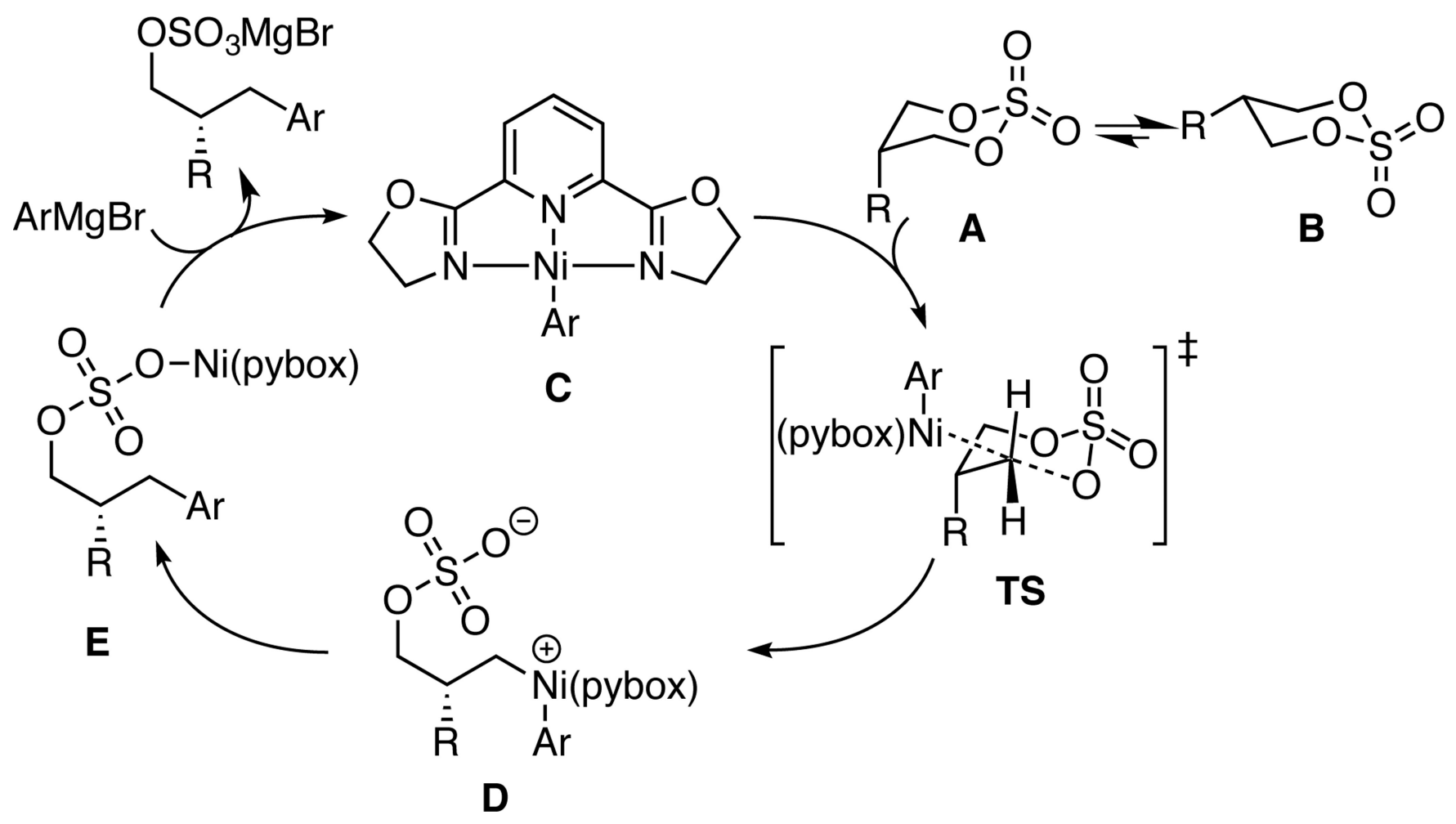

Scheme 4.

Generalized Mechanism for Ni(pybox)-Catalyzed Kumada Coupling of Cyclic Sulfates. 
Table 1

Survey of Ligand Effects in Asymmetric Ni-Catalyzed Reaction of PhMgBr and Cyclic Sulfate 1. ${ }^{a}$<smiles>CC1COS(=O)(=O)OC1</smiles>

1

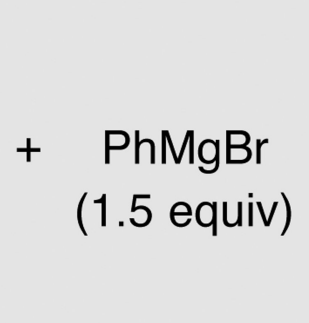

(1.5 equiv)

(1.5 equiv)

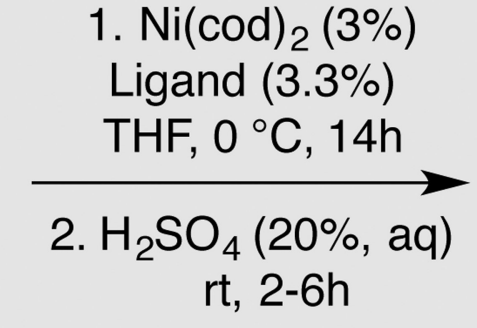

rt, $2-6 h$

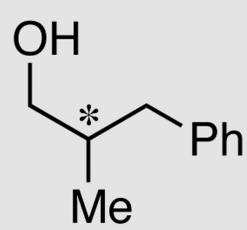

2

$$
\begin{aligned}
& \mathrm{Ar}=3,5-t \mathrm{Bu}_{2} \mathrm{Ph} \\
& \text { 19\% y, 50:50 er }
\end{aligned}
$$<smiles>CC1(C)OC2[C@H](O1)C(Br)(Br)OP(c1ccccc1)OC2(Br)Br</smiles><smiles>c1ccc(-c2ccccn2)nc1</smiles>

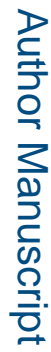<smiles>O=S(=O)(O)c1ccc(-c2ccccn2)nc1-c1ccccn1</smiles><smiles>Br[C@H]1COC(C2=N[C@H](Br)CO2)=N1</smiles>

$43 \%$ y, 59:41 er<smiles>CC(C)(C1=N[C@@H](c2ccccc2)CO1)C1=N[C@@H](c2ccccc2)CO1</smiles>

$18 \%$ y, 50:50 er<smiles>[R]C1COC(c2cccc(C3=N[C@H]([R])CO3)n2)=N1</smiles>

L1 ( $\mathrm{R}=i-\mathrm{Pr}): 44 \%$ y, 62:38 er L2 $(\mathrm{R}=t$-Bu): 33\% y, 54:46 er L3 ( $R=P h): 33 \%$ y, 80:20 er L4 $^{b}(\mathrm{R}=3,5-x y|y|): 72 \%$ y, 87:13 er L5 ( $\left.R=3,5-\mathrm{Et}_{2} \mathrm{Ph}\right): 58 \%: 92: 8 \mathrm{er}$ L6 ( $\left.R=3,5-t \mathrm{Bu}_{2} \mathrm{Ph}\right): 53 \%: 86: 14$ er<smiles>c1ccc([C@H]2COC(c3ccccn3)=N2)cc1</smiles>

$21 \%$ y, $76: 24$ er

\footnotetext{
${ }^{a}$ Yield represents isolated yield after purification by silica gel chromatography. Enantiomer ratios were determined by SFC analysis on chiral stationary phase.

${ }^{b}$ Acid hydrolysis for $24 \mathrm{~h}$ at room temperature.
} 
Table 2

Substrate Scope in Enantioselective Kumada Couplings of Prochiral Cyclic Sulfates. ${ }^{a}$

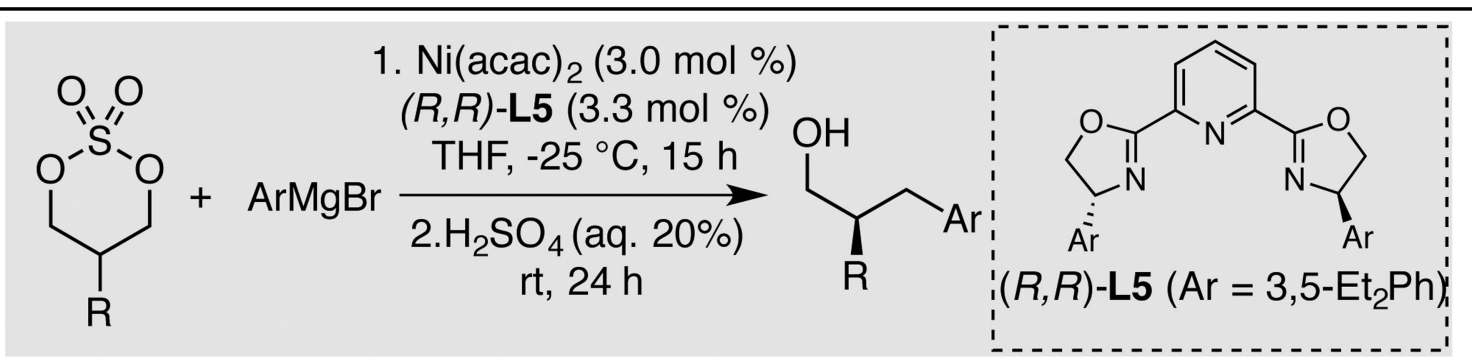

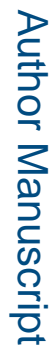

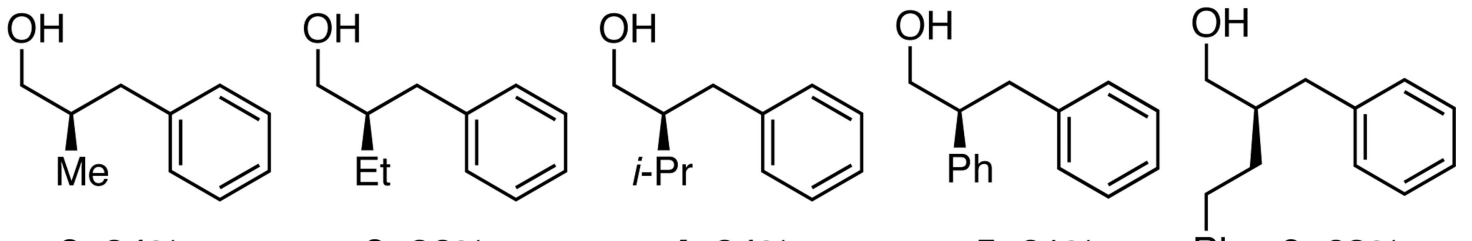
2, $84 \%$ y
$3,86 \%$ y
4, $84 \%$ y
$5,61 \%$ y
$\mathrm{Ph}$ 6, 63\% y
96:4 er
95:5 er
96:4 er
88:12: er
88:12: er<smiles>OC[C@H](COc1ccccc1)Cc1ccccc1</smiles><smiles>Cc1ccc(C[C@@H](C)CO)cc1</smiles><smiles>Cc1cccc(C[C@@H](C)CO)c1</smiles><smiles>C[C@@H](CO)Cc1ccc(C(C)(C)C)cc1</smiles>
7, $81 \%$ y
8, $98 \%$ y
92:8 er
95:5 er

9, 83\% y

95:5 er

10, $90 \%$ y

94:6 er

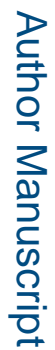<smiles>COc1ccc(C[C@@H](C)CO)cc1</smiles><smiles>COc1cccc(C[C@@H](C)CO)c1</smiles>

$11,80 \%$ y

95:5 er

$12,86 \%$ y

89:11 er<smiles>[Y16]C(CO)Cc1ccc2c(c1)OCO2</smiles><smiles>C[C@H](CO)Cc1ccc(F)cc1</smiles>

$13,81 \%$ y 94:6 er

$14^{b}, 91 \%$ y

93:7 er

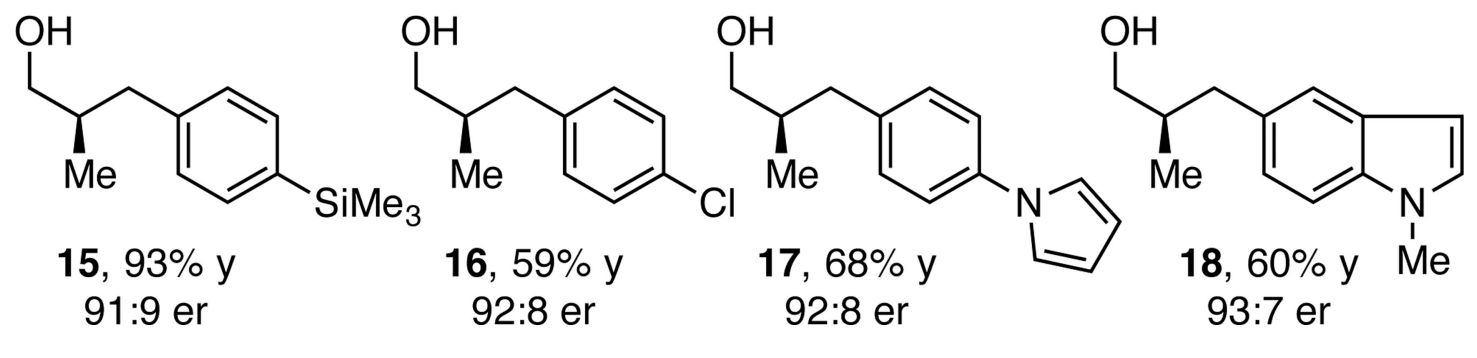

${ }^{a}$ Reactions employed $0.3 \mathrm{mmol}$ of cyclic sulfate and 1.5 equiv $\mathrm{ArMgBr}$ in THF. Results are an average of two experiments. Yield represents isolated yield after purification by silica gel chromatography. Enantiomer ratios were determined by SFC analysis on chiral stationary phase.

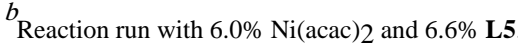

